Original Contribution

\title{
METAFILLACTIC EFFICIENCY OF FLORFENICOL, APPLIED TO THE FODDER OF THE PIGS FROM THE FATTENING INFECTED WITH MYCOPLASMA HYOPNEUMONIAE
}

\author{
R. Pepovich* \\ Department of Infectious Pathology \& Hygiene, Technology and Control of Foods from Animal \\ Origin, Faculty of Veterinary Medicine, University of Forestry, Sofia, Bulgaria
}

\begin{abstract}
The field research has been conducted with 390 pigs, which have are the same weight and age and are affected by a subclinical form of enzootic pneumonia. The pigs have been divided into two groups. First group has been receiving concentrated forage, combined with the antibiotic medicine Florfenicol in dose $2.0 \mathrm{~kg}$ Feniveex-2\% premix/1000 kg fodder, for 7 days. Second group has been receiving the same fodder, but with the supplement Tylosin in dose $1.0 \mathrm{~kg}$ Tylovet-10\% premix/1000 kg, for 21 days (positive control). The pigs from both groups have been observed for a period of 30 days, aftere the beginning of the treatment with medical fodder. The field research has demonstrated, that the Florfenicol used in the beginning of the fattening has proved effective in the control of the enzootic pneumonia, in comparison with the group that has been receiving Tylosin. It is established improvement of the clinical status of the animals, decrease in death, lowering the damage of the lungs and an increase in the average daily growth.
\end{abstract}

Key words: Mycoplasma hyopneumoniae, pigs, Florfenicol, metaphylaxis.

\section{INTRODUCTION}

The enzootic pneumonia is a chronic, contagious pig disease caused by Mycoplasma hyopneumoniae (M. hyopneumoniae) (1). The disease cause the serious economic damages in pigs - breeding all over the world, although, it is difficult to determine the specific economic effect of the mycoplasmal pneumonia on a herd level. A review from different studies shows that the disease leads to decreasing of the average daily growth approximately with $17 \%$ and with $14 \%$ it decreases the convertion of forage. It is also proved that for every $10 \%$ of affected from pneumonia lungs the average daily growth decreases with 37 grams. A survey, made in USA, shows that the cost for a pig, that is suffering from a mycoplasmal pneumonia, is $4.08 \$$. The annual cost for the whole country counts approximately 367 billion dollars (2).

Effective antibiotics applied with the food and water of the pigs is an effective control of the

\footnotetext{
*Correspondence to: ROMAN PEPOVICH, Department of Infectious Pathology \& Hygiene, Technology and Control of Foods from Animal Origin, Faculty of Veterinary Medicine, University of Forestry, Sofia, Bulgaria, E-mail: rpepovich@gmail.com
}

Respiratory diseases, including the enzootic pneumonia (EP). This leads to an improvement of the economic parameters - better conversion of the forage and increased average daily growth, also to a decreasing of the clinical symptoms and lung lesions of the disease and prevents it from secondary bacterial infection $(1,3)$. From the other hand, the inappropriate application of antibiotics increases the possibility of antimicrobial resistance and antimicrobial residue in the slaughtered pig corpses (4). And for that reason, after the end of the treatment new cases of the disease could be presented $(5,6)$.

The purpose of this field research was to evaluate the effect of applying Florfenicol in the forage to clinical and economic parameters of pigs, suffering from enzootic pneumonia.

\section{MATERIALS AND METHODS Study animals}

The field research was conduct with 390 pigs, equal by age and weight, affected by a subclinical form of enzootic pneumonia. The organization of the technological process in the pig farm involved weaning the pigs at 35 days of age and with a period of growing old of 73 days. Immediately after transitioning the pigs 
into the fattening group we formed two study groups:

- First group - 205 pigs, 15 weeks old with average live weight of $55 \pm 2.15 \mathrm{~kg}$. All of the animals have been given concentrated forage, combined with the antibiotic medicine Florfenicol (Feniveex-2\% premix $^{\circledR}$, Reveex), with the following application: $\quad 2.0 \mathrm{~kg} \quad$ Feniveex-2\% premix $^{\circledR} / 1000 \mathrm{~kg}$ fodder for 7 days.

- Second group - 185 pigs (positive control), 15 weeks old with average live weight of $55 \pm 3.07 \mathrm{~kg}$, fed with the special forage mix "grower". At the early stages of the fattening of the pigs their forage was modified with the antibiotic medicine Tylosin (Tylovet-10\% premix $^{\circledR}$, Biovet), with the following application: $1.0 \mathrm{~kg}$ Tylovet-10\% premix $^{\circledR} / 1000 \mathrm{~kg}$ fodder for 21 days.

All of the rooms, used for the experiment, were thoroughly cleaned and disinfected. All of the medical forages were made at the pig farm and were given to the pigs ad libitum. The water was also given ad libitum, from autonomous nipple water troughs. The pigs from the two groups were bred by the same conditions. All of the parameters of the ventilation, lightning and temperature in the rooms were exactly the same as the requirements of the GMP for a contemporary intensive pig farm.

\section{Clinical studies}

We made the observation over the pigs for 30 days after starting the medical forages. We monitored the pigs for the following indicators every day: rectal temperature, general condition, dyspnea, cough and nasal discharge. The different medical indicators were ranked by a specific scale, described by Lang et al. (7), and we described the clinical condition of the pigs as very good, good, satisfactory and poor.

\section{Necropsy}

Pathologoanatomical exams were performed to all of the dead and killed by emergency pigs. The severity and extent of pulmonary lesions typical for EP in percentage from the whole pulmonary surface were evaluated according to the Kristensen et al. (8).

\section{Serological test}

From all of the two groups of pigs were taken 20 blood samples in total before the treatment (D0) and at the end of the experiment (D30). The serums were tested for proving the presence of specific antibodies against $M$. hyopneumoniae. The test were performed by blocking ELISA with the help of the testing kit
Ingezim M. hyo compact $^{\circledR}$ (Ingenaza-Spain), according to the instructions of the manufacturer.

\section{Polymerase chain reaction (PCR)}

We have achieved the confirmation of $M$. hyopneumoniae in 20 nasal swabs of pigs via PCR with one primer couple from the „Jena Bioscience" company: MHP950-1L (5'-AGG $A A C$ ACC ATC GCG ATT TTT A-3 $3^{l}$ ) and MHP950-1R (5'-ATA AAA ATG GCA TTC CTTTTC $A-3^{l}$ ). They are responsible for the synthesis of a DNA amplification product of $910 \mathrm{bp}$ in size that is specific for $M$. hyopneumoniae. We have isolated the bacterial DNA with Buccal Swab DNA Kit (Geneshun Biotech, China). For the reaction we have used $3.5 \mu \mathrm{l}$ of DNA, 10 pmol of each primer, 12.5 $\mu 12 \times$ PCR Master Mix, and distilled water up to $25 \mu \mathrm{l}$. We have performed the amplification in thermocycler with the following temperature sequence: initial denaturation $-95{ }^{\circ} \mathrm{C} / 5 \mathrm{~min}$; 35 cycles of amplification including denaturation $-95{ }^{\circ} \mathrm{C} / 30 \mathrm{sec}$; annealing - 53.5 ${ }^{\circ} \mathrm{C} / 40 \mathrm{sec}$; elongation $-72{ }^{\circ} \mathrm{C} / 1 \mathrm{~min}$; final elongation $-72{ }^{\circ} \mathrm{C} / 7 \mathrm{~min}$, followed by cooling to $4{ }^{\circ} \mathrm{C}$. We controlled the obtained DNA and the PCR products by gel electrophoresis at 120 $\mathrm{V}$ for 40 minutes.

\section{Nested polymerase chain reaction (nPCR)}

All samples of nasal swabs in PCR, were further analyzed using nPCR. The sequences of the primers (Jena Bioscience ${ }^{\circledR}$ ) used for nPCR are present below: MHP950-2L (5 ${ }^{1}$ CCC TTT GTC TTA ATT TTT GCA A-3 ${ }^{I}$ ) and MHP950-2R (5'-GCC GAT TCT AGT ACC $C T A$ ATC $C-3^{I}$ ). They are responsible for the synthesis of DNA amplified specific for $M$. hyopneumoniae product with a size $807 \mathrm{bp}$. For the reaction: $1.0 \mu \mathrm{l}$ PCR product, $2.0 \mu 1$ mixed primers (2L-2R), $12.5 \mu$ l MasterMix and $9.5 \mu 1$ distilled water, were used. The amplification cycle consisted of an initial 5 min denaturation at $95{ }^{\circ} \mathrm{C}$, followed by 35 cycles of $30 \mathrm{sec}$ at $95{ }^{\circ} \mathrm{C}$; annealing - 56.5 ${ }^{\circ} \mathrm{C} / 40 \mathrm{sec}$; elongation $-72{ }^{\circ} \mathrm{C} / 1 \mathrm{~min}$; final elongation $-72{ }^{\circ} \mathrm{C} / 7 \mathrm{~min}$, followed by cooling to $4{ }^{\circ} \mathrm{C}$. Obtained PCR products were visualized in gel electrophoresis $(120 \mathrm{~V}$ for 40 min).

\section{Statistical analysis}

Statistical analysis was performed using the StatMost software (StatMost 3.6, Dataxiom Software, 2003). Data represent mean values with standard error of the means (Mean \pm SE) determine by one-way ANOVA. Results were considered statistically significantly different when $P<0.05$. 


\section{RESULTS AND DISCUSSION}

The economic and epidemiological results from the clinical study of applying Florfenicol to the forage of pigs for fattening and to control the EP are shown on Table 1. From the results it became clear that the symptoms of a respiratory disease are presented at both groups. From the other hand morbility rate is with $20.1 \%$ lower in the group where the pigs were treated methafilactic with Florfenicol compared to the positive control group, where the pigs were treated with Tylosin-premix. In mortality rate calculated as a total number of dead animals from all of the receptive animals in the group, is lower in the group where the animals were medicated with Florfenicol
$(0.5 \%)$, compared to the other one where the animals were treated with Tylosin. Best economic results we received from the group, treated with Florfenicol-premix. They refers to obtaining a higher average daily gain of $50 \mathrm{~g}$ more than those treated with Tylosin and to higher percent of clinically recovery pigs, respectively $97.5 \%$ for the ones treated with Florfenicol and $94.6 \%$ for the other onestreated with Tylosin. Our results confirm the information from Ciprián et al. (9) concerning significantly higher average daily weight gain of the Florfenicol-treated pigs than that of the non-treated ones, affected of chronic infection of M. hyopneumoniae.

Table 1. Economic and epidemiological results of the clinical testing of Florfenicol-premix in fattening pigs, affected by EP

\begin{tabular}{|c|c|c|c|}
\hline Parameters & Units & $\begin{array}{c}\text { I group } \\
\text { (experimental) }\end{array}$ & $\begin{array}{l}\text { II group } \\
\text { (positive control) }\end{array}$ \\
\hline 1. Treated pigs & $\mathrm{n}$ & 205 & 185 \\
\hline 2. Medicament & - & $\begin{array}{c}\text { Feniveex } 2 \%- \\
\text { premix }^{\circledR}\end{array}$ & $\begin{array}{l}\text { Tylovet } 10 \% \text { - } \\
\text { premix }^{\circledR}\end{array}$ \\
\hline 3. Active substance & - & $\begin{array}{l}\text { Florfenicol - } \\
2.0 \mathrm{~g} / 100 \mathrm{~g}\end{array}$ & $\begin{array}{c}\text { Tylosine phosphas } \\
- \\
100.0 \mathrm{mg} / 1 \mathrm{~g}\end{array}$ \\
\hline 4. Dose & $\kappa g / t$ & 2.0 & 1.0 \\
\hline 5. Course of treatment & days & 7 & 21 \\
\hline 6. Start of treatment & weeks & 15 & 15 \\
\hline 7. Finish of treatment & weeks & 16 & 18 \\
\hline 8. Duration of the experiment & days & 30 & 30 \\
\hline $\begin{array}{l}\text { 9. Average live weight at beginning of } \\
\text { experiment }\end{array}$ & $\mathrm{kg}$ & $55 \pm 2.15^{*}$ & $55 \pm 3.07 *$ \\
\hline $\begin{array}{l}\text { 10. Average live weight at the end of the } \\
\text { experiment }\end{array}$ & $\mathrm{kg}$ & $79 \pm 3.29 * *$ & $77.5 \pm 2.83$ \\
\hline 11. Derived growth & $\mathrm{kg}$ & 24 & 22.5 \\
\hline 12. Average daily gain & $\mathrm{kg}$ & 0.800 & 0.750 \\
\hline \multirow{2}{*}{ 13. Morbility rate } & $\mathrm{n}$ & 12 & 48 \\
\hline & $\%$ & 5.8 & 25.9 \\
\hline \multirow{2}{*}{ 14. Mortality rate } & $\mathrm{n}$ & 1 & 2 \\
\hline & $\%$ & 0.5 & 1.1 \\
\hline \multirow{2}{*}{ 15. Emergency slaughtered } & $\mathrm{n}$ & 4 & 8 \\
\hline & $\%$ & 2.0 & 4.3 \\
\hline \multirow{2}{*}{ 16. Clinically healed } & $\mathrm{n}$ & 200 & 175 \\
\hline & $\%$ & 97.5 & 94.6 \\
\hline
\end{tabular}

$* p<0.05 \quad * * p<0.01 \quad * * * p<0.001$

The clinical efficiency of Florfenicol-premix against mycoplasmal pneumonia is presented at Table 2. All of the collected data shows that during the first 7 days of the experiment, all of the pigs that have been given Florfenicol are in better medical condition (69.3\%) compared to the other group (64.9\%). During this period at both groups there are no dead or slaughtered animals. During the period from $8^{\text {th }}$ to $14^{\text {th }}$ day the difference between the pigs in very good medical condition at both groups significantly starts to increase, as in the first group the percent is $64.9 \%$ and in the second one $32.4 \%$. Clinical symptoms of a respiratory disease (e.g. cough, nose secretion, dyspnea, anorexia, depression) were presented as follow $1.5 \%$ in the first group and $11.4 \%$ in the second group of pigs. In both groups the percentage of 
deaths reached $0.5 \%$, while the percentage of slaughtered pigs was $1.1 \%$ more in Tylosin treated. During the third week (from $15^{\text {th }}$ to $21^{\text {st }}$ day) the tendency for a higher morbility rate and mortality rate at the second group (treated with Tylosin) were retained. During the end of the methafilactic course (from $22^{\text {nd }}$ to $30^{\text {th }}$ day) the medical condition of the pigs from the first group remain as "very good" in $57.2 \%$ in the cases and only in $1.0 \%$ symptoms of a respiratory disease were presented. Among the pigs in the second group only $20.4 \%$ were in "very good" condition and $3.4 \%$ of them have shown symptoms of a respiratory disease. During this final stage of methafilactic in both groups, we did not record any differences in the percentage of deaths and slaughtered pigs. Similar results are obtained from Ciprián et al. (9) in Florfenicol treated pigs which have lower body temperature, lighter cough and dyspnea, compared with untreated pigs affected by M. hyopneumoniae infection.

Table 2. Clinical status of fattening pigs treated with Florfenicol-premix and Tylosin-premix

\begin{tabular}{|c|c|c|c|c|c|c|c|}
\hline \multirow[b]{2}{*}{$\begin{array}{c}\text { Treated } \\
\text { group }\end{array}$} & \multirow[b]{2}{*}{$\begin{array}{c}\text { Day of } \\
\text { experience }\end{array}$} & \multicolumn{6}{|c|}{ Clinical status } \\
\hline & & $\begin{array}{l}\text { very } \\
\text { good } \\
(\%)\end{array}$ & $\begin{array}{l}\text { good } \\
(\%)\end{array}$ & $\begin{array}{c}\text { satisfactory } \\
(\%)\end{array}$ & $\begin{array}{l}\text { poor } \\
(\%)\end{array}$ & $\begin{array}{l}\text { died } \\
(\%)\end{array}$ & $\begin{array}{c}\text { slaughtered } \\
(\%)\end{array}$ \\
\hline \multirow{4}{*}{$\begin{array}{c}\text { Florfenicol } \\
\qquad(n=205)\end{array}$} & 7 & 69.3 & 19.0 & 9.8 & 1.9 & 0 & 0 \\
\hline & 14 & 64.9 & 23.9 & 8.7 & 1.5 & 0.5 & 0.5 \\
\hline & 21 & 60.1 & 30.0 & 7.4 & 1.5 & 0 & 1.0 \\
\hline & 30 & 57.2 & 31.8 & 9.5 & 1.0 & 0 & 0.5 \\
\hline \multirow{4}{*}{$\begin{array}{l}\text { Tylosin } \\
(n=185)\end{array}$} & 7 & 64.9 & 27.0 & 5.4 & 2.7 & 0 & 0 \\
\hline & 14 & 32.4 & 37.8 & 16.3 & 11.4 & 0.5 & 1.6 \\
\hline & 21 & 22.1 & 48.6 & 17.7 & 8.8 & 0.6 & 2.2 \\
\hline & 30 & 20.5 & 59.7 & 15.9 & 3.4 & 0 & 0.5 \\
\hline
\end{tabular}

The results of the pathological exams of the dead and dropped out pigs during the research are presented at Figure 1. The table shows that amond the pigs treated with Florfenicol predominate lungs without any lesions which are common for EP. At both groups there were no differences among the lungs affected slightly (with lesions to $10 \%$ of the lungs surface). In the second group (treated with Tylosin) the percentage of moderately affected lungs was higher (lesions from $11 \%$ to $20 \%$ of the lungs surface). Among the pigs, treated with Florfenicol there were no severe cases of lungs lesion (lesion with more than 20\% affected area of the lungs) due to $M$. hyopneumoniae, which were very common among the pigs treated with Tylosin. Our results are similar with the results received from Ciprián et al. (9) concerning lower average percentage of pneumonic gross lesions in treated pigs with Florfenicol, compared to $M$. hyopneumoniae infected non-medicated.

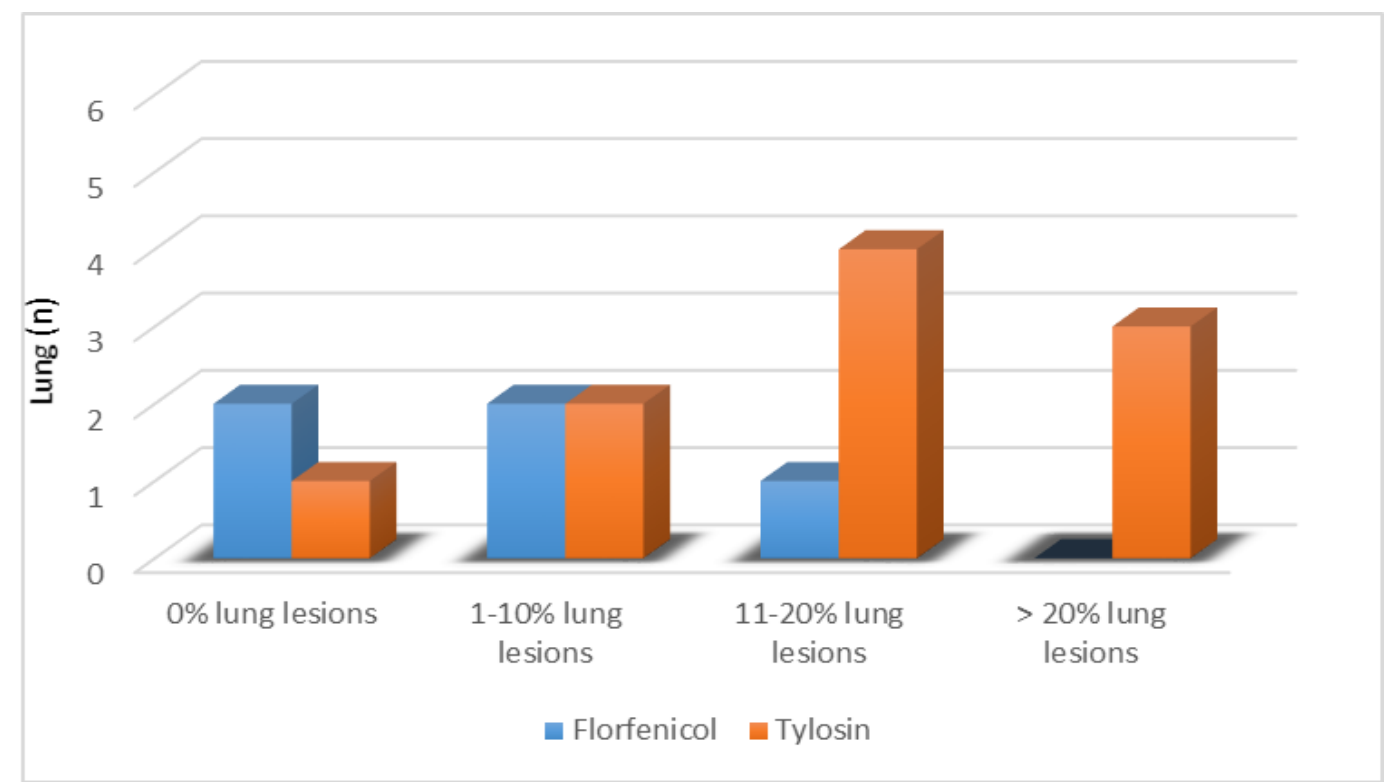

Figure 1. Assessment of lung lesions caused by M. hyopneumoniae in both treatment groups 
The results of the serological experiments show that before the treatment of the animals with Florfenicol the percentage of seropositive pigs is $50 \%$ (5/10 pigs) and in the end of the experiment it increases up to $70 \%$ (7/10 pigs). In the control group treated with Tylosin there weren't registrated differences in the percentage of the seropositive pigs before the treatment $-80 \%$ ( $8 / 10$ pigs) in the end of the experiment $-80 \%$ ( $8 / 10$ pigs). The short course of medicating the pigs with Florfenicol (7 days) led to enough natural exposition with the pathogen, which can stimulate effectively the active immunity against $M$. hyopneumoniae. The long treatment of the pigs with Tylosin (21 days) in the control group may be the cause some animals to remain immunologically defenseless. This can cause risk of repeating infections with M. hyopneumoniae at stopping medication. Our results are similar with the results received from Walter at al. (10) and Del Pozo Sacristan et al. (11). The analysis of the results from the molecular-biological exams from a nose secretion didn't show any significant differences between the two groups. In the group treated with Florfenicol the percentage of nasal secretions positive for $M$. hyopneumoniae before the treatment is $70 \%$ ( $7 / 10$ pigs) and in the end of the experiment $80 \%$ (8/10 pigs). In the control group treated with Tylosin the percentage of positive for $M$. hyopneumoniae nasal secretions before the treatment is $90 \%$ (9/10 pigs) and in the end of the experiment $-100 \%$ (10/10 pigs). This leads to conclusion that the clinical recovery after the treatment is not accompanied with full disappearance of the pathogen which is confirmed by the existing lung lesions in both groups, reported also by Thacker (1) (Table 3).

Table 3. Results of serological and molecular-biological studies of fattening pigs affected by EP

\begin{tabular}{|c|c|c|c|c|}
\hline \multirow{4}{*}{$\begin{array}{c}\text { Treated } \\
\text { group }\end{array}$} & \multicolumn{4}{|c|}{ Number of seropositive and nPCR-positive pigs/total number of pigs sampled } \\
\cline { 2 - 5 } & \multicolumn{3}{|c|}{ ELISA } & \multicolumn{2}{c|}{ nPCR } \\
\cline { 2 - 5 } & $\begin{array}{c}\text { Before treatment } \\
\text { (D0) }\end{array}$ & $\begin{array}{c}\text { After treatment } \\
\text { (D30) }\end{array}$ & $\begin{array}{c}\text { Before treatment } \\
\text { (D0) }\end{array}$ & $\begin{array}{c}\text { After treatment } \\
\text { (D30) }\end{array}$ \\
\hline Florfenicol & $5 / 10$ & $7 / 10$ & $7 / 10$ & $8 / 10$ \\
\hline Tylosin & $8 / 10$ & $8 / 10$ & $9 / 10$ & $10 / 10$ \\
\hline
\end{tabular}

The results from our research show that the methafilactic treatment of pigs with Florfenicol $(2.0 \mathrm{~kg} / \mathrm{t})$ added to the forage leads to reducing the clinical symptoms and lungs lesions and all of this leads to a better economic results. Similar to our results are ones from Del Pozo Sacristan et al. (12) research. Their research was to determine the efficiency of a single treatment of pigs with Florfenicol in dosage 30 $\mathrm{mg} / \mathrm{kg}$ at experimental infection with $M$. hyopneumoniae. The good results of applying Florfenicol to control the mycoplasmal pneumonia and unsatisfactory effect of applying Tylosin are in unison with Vicca et al. (13) and Vicca (3) research which describes first cases of acquired resistance of field strains of $M$. hyopneumoniae against macrolides, lincosamides and fluoroquinolones and the absence of one against Florfenicol.

At the stationary farms for EP as a prophylactic precaution is suited medicine to be given along with the forage. This makes easier the applying of the medicine and also it reduces the stress from the animals. And this is the reason why the medical forages are preferred in the industrial pig-breeding where the pigs must be treated as a group. Important moment in the enzootic pneumonia`s treatment the proper choice of antibiotic which is in connection with the increasing multi resistance to antimicrobials. This must pay attention to the veterinary doctors that they have to be applied whenever they are needed and they have to be applied properly.

\section{CONCLUSION}

It is established a good methafilactic efficiency of Florfenicol applied in dose $2.0 \mathrm{~kg}$ Feniveex$2 \%$ premix $/ 1000 \mathrm{~kg}$ forage for 7 days to control the enzootic pneumonia in pigs. This is presented by reducing the clinical symptoms and lung lesions and by increasing the average daily gain.

\section{REFERENCES}

1. Thacker, E. L., Mycoplasmal diseases. In: Leman, A.D., Straw, B.E., D‘Allaire, S., Mengeling, W.L., and Taylor, D.J., (Ed.), Diseases of Swine, $9^{\text {th }}$ ed., Iowa State University Press, Ames, IA, pp. 701-717, 2006.

2. Thacker, E. and B. Thacker, Mycoplasmal pneumonia of swine. Pork Information Gateway, 1-4, 2012.

3. Vicca, J., Virulence and antimicrobial susceptibility of Mycoplasma 
hyopneumoniae isolates from pigs. Ph.D. thesis, Gent University, Belgium, 2005.

4. Maes, D., Deluyker, H., Verdonck, M., Castryck, F., Miry, C., Vrijens, B., Verbeke, W., Viaene, J., de, K.A., Effect of vaccination against Mycoplasma hyopneumoniae in pig herds with an allin/all-out production system. Vaccine, 17:1024-1034, 1999.

5. Wallgren, P., J. Vallgarda, M. Lindberg, L. Eliason-Selling, The efficacy of different vaccination strategies against Mycoplasma hyopneumoniae. In Proc. of the 16-th IPVS Congress, Melbourne, Australia, pp. 461, 2000.

6. Stipkovits, L., D. Miller, R. Glavits, L. Fodor, D. Burch, Treatment of pigs experimentally infected with Mycoplasma hyopneumoniae, Pasteurella multocida, and Actinobacillus pleuropneumoniae with various antibiotics. Can. J. Vet. Rec., 65:213-222, 2001.

7. Lang I., M. Rose, E. Thomas and E. Zschiesche, A field study of cefquinome for the treatment of pigs with respiratory disease. Revue Méd. Vét., 153(8-9):575580, 2002.

8. Kristensen, Ch., J. Vinther, B. Svensmark, P. Baekbo, A field evalution of two vaccines against Mycoplasma hyopneumoniae infection in pigs. Acta Veterinaria Scandinavica, 56(24):1-7, 2014.

9. Ciprián, A., J.M. Palacios, D. Quintanar, L. Batista, G. Colmenares, T. Cruz, A.
Romero, W. Schnitzlein, S. Mendoza, Florfenicol feed supplemented decrease the clinical effects of Mycoplasma hyopneumoniae experimental infection in swine in México. Research in Veterinary Science, 92:191-196, 2012.

10.Walter D., Holck, J.T., Sornsen, S., Hagen, C., Harris I.T., The effect of a metaphylactic pulse dosing in-feed antimicrobial strategy on finishing pig health and performance. Swine Health and Production, 8:65-71, 2000.

11.Del Pozo Sacristán, R., A. López Rodríguez, A. Sierens, K. Vranckx, F. Boyen, A. Dereu, F. Haesebrouck, D. Maes, Efficacy of in-feed medication with chlortetracycline in a farrow-tofinish herd against a clinical outbreak of respiratory disease in fattening pigs. Veterinary Record, 171(25):645, 2012a.

12.Del Pozo Sacristan, R., Thiry J., Vranckx K., Lopez Rodriguez A., Chiers K., Haesebrouck F., Thomas E., Maes D., Efficacy of florfenicol injection in the treatment of Mycoplasma hyopneumoniae induced respiratory disease in pigs. Veterinary Journal, 194(3):420-422, 2012b.

13.Vicca, J., Stakenborg, T., Maes, D., Butaye, P., Peeters, J., de Kruif, A., Haesebrouck, F., In vitro susceptibilities of Mycoplasma hyopneumoniae field isolates. Antimicrob. Agents Chemother, 48(11):4470-4472, 2004. 